\title{
Adsorptive Mass Transport of Dye on Rice Husk Ash
}

\author{
Debasish Sarkar, Amitava Bandyopadhyay ${ }^{*}$ \\ Department of Chemical Engineering, University of Calcutta, Kolkata, India \\ E-mail:amitava.bandy@gmail.com \\ Received December 13, 2009; revised January 16, 2010; accepted February 10, 2010
}

\begin{abstract}
Experimentations have been carried out to characterize the adsorption of Methylene Blue (MB) and Congo Red (CR) dyes in the aqueous phase onto Rice Husk Ash (RHA). Theoretically analyses are also made for describing the sorption and diffusion processes. The effective pore diffusivities of the dye molecules studied in RHA are determined by a suitable global optimization technique. The depth of penetration, on the other hand, has been estimated for various initial concentrations of dyes. Theoretically predicted concentration profiles are compared with the experimental values at different initial concentrations of these dyes. Such comparative studies indicate that the predicted values are in excellent agreement with the experimental values.
\end{abstract}

Keywords: Congo Red, Diffusivity, Dye Adsorption, Film Mass Transfer, Methylene Blue, Rice Husk Ash

\section{Introduction}

Textile industries, dye intermediate manufacturing units and industries engaged in dyeing/bleaching of textiles generate colored effluent with high values of Chemical Oxygen Demand (COD) and Bio-Chemical Oxygen Demand (BOD). Presence of dyes imparts such higher values of these parameters. If water bodies receiving such waste water containing dyes are not properly treated then adverse environmental impacts are noticed on contact with this wastewater, like allergic dermatitis, skin irritation and mutation etc. to humans [1] since many of these dyes were reported to be carcinogenic and highly toxic to humans. Such discharge of waste water without proper treatment also reduces the level of photosynthesis to the water bodies. Thus it is imperative to treat colored waste water prior to discharge. Colored waste water can be treated by several methods, like coagulation, membrane separation, biological treatment, adsorption, chemical oxidation (using chlorine, Fenton's reagent and ozone) and photo-oxidation (using UV light, $\mathrm{TiO}_{2}$ in presence of visible light). Adsorption among these methods is included in almost all waste water treatment facilities as a polishing stage for meeting the effluent discharge standards. Available literature revealed that these dyes were investigated on various adsorbents, like acid activated red mud [2], dehydrated wheat bran [3], activated carbon prepared from Bamboo [4], rice husk [5], adsorbents prepared from Parthenium hysterophorus
[6], nitric-acid treated water-hyacinth [7], algae Gelidium, an industrial waste from agar extraction process and a composite material obtained by immobilization of the algal waste with polyacrylonitrile [8], activated carbon [9], beer brewery waste [10], silica nano-sheets derived from vermiculite via acid leaching [11], series of $\mathrm{N}, \mathrm{O}$-carboxy-methyl-chitosan/montmorillonite nanocomposites prepared by controlling the molar ratios of $\mathrm{N}, \mathrm{O}-$ carboxy-methyl-chitosan and montmorillonite [12], bentonite [13], garlic peel an agricultural waste [14], clay minerals of bentonite, kaolin and zeolite [15], cetyl trimethyl ammonium bromide impregnated chitosan beads [16], maghemite nanoparticles $\left(\gamma-\mathrm{Fe}_{2} \mathrm{O}_{3}\right)$ [17] and jute stick powder [18].

Present investigation therefore, aims at assessing the adsorption characteristics of aqueous solutions of Methylene Blue (MB) and Congo Red (CR) as synthetic dye containing waste water on a suitable low cost and locally available adsorbent, Rice Husk Ash (RHA). Studies carried out under batch mode with agitation are important for generating equilibrium and kinetic data, from which the effective pore diffusivity of the adsorbate can be evaluated. The performance of industrial packed bed adsorber generally depends on the pore diffusivity, an intrinsic process design parameter. Adsorptive mass transfer is governed by the external liquid film as well as the pore diffusion resistances in series. Vigorous agitation is generally adopted in batch adsorption studies and as a result, the liquid film resistance under this circumstance could be neglected. This in effect causes the ad- 
sorptive mass transport to be controlled by the resistance offered from the pore diffusion. This is characterized by the concentration independent (due to very low feed concentration) effective pore diffusion coefficient $\left(D_{0}\right)$ of the adsorbate.

Detailed analysis of the existing literature indicated that batch adsorption studies on the removal of dyes from aqueous solution have so far been conducted without dealing with the mass transfer analysis. Jena et al. [19] however, reported on the generalized shrinking core model for analyzing the batch adsorption behavior of organic molecules in the aqueous phase using porous silica as well as activated carbon. In this article, an attempt has been made to characterize pore diffusion of $\mathrm{MB}$ and CR dye molecules by adsorption onto RHA using unsteady state mass- and component- balance. The development of transient concentration profile in the bulk fluid and concentration distribution of the dye within the RHA particles in terms of various pertinent variables of the system is the main objective of the formulation part of the model. Model intended to be developed could also be able to estimate the pore diffusivity for different dye molecules into RHA particles.

\section{Model Development for Sorption and Diffusion of Dye}

The process of uptake of dye molecules by RHA comprises its adsorption at the surface followed by diffusion within RHA particles. The RHA particles were assumed to be spherical and of equal size (diameter) for the ease of mathematical modeling. The unsteady state diffusion of a species in a spherical particle can be described by the following equation

$$
\frac{\partial C}{\partial t}=\frac{1}{r^{2}} \frac{\partial}{\partial r}\left(r^{2} D_{0} \frac{\partial C}{\partial r}\right)
$$

The effective pore diffusivity $\left(D_{0}\right)$ was assumed to be independent of concentration. The above equation can be solved analytically for the case of unsteady state surface concentration $\left[C_{0}=C_{0}(t)\right]$ and zero initial concentration of dye within RHA [20] to obtain the following transient concentration distribution

$$
\begin{aligned}
& C(r, t)= \\
& \frac{2}{R r} \sum_{n=1}^{\infty}(-1)^{n+1} n \pi D_{0} \sin \frac{n \pi r}{R} \cdot e^{\frac{-D_{0} n^{2} \pi^{2} t}{R^{2}}} \int_{0}^{t} C_{0}\left(t^{\prime}\right) e^{\frac{D_{0} n^{2} \pi^{2} t^{\prime}}{R^{2}}} d t^{\prime}
\end{aligned}
$$

The amount of dye uptake at any instant of time $t$ per unit mass of the adsorbate can be obtained from the Equation (2) as

$$
\begin{gathered}
Y(t)=\frac{\int_{0}^{R} C(r, t) 4 \pi r^{2} d r}{4 / 3 \pi R^{3} \rho_{P}}= \\
\frac{6 D_{0}}{R^{2} \rho_{P}} \sum_{n=1}^{\infty} e^{\frac{-D_{0} n^{2} \pi^{2} t}{R^{2}}} \int_{0}^{t} C_{0}\left(t^{\prime}\right) e^{\frac{D_{0} n^{2} \pi^{2} t^{\prime}}{R^{2}}} d t^{\prime}
\end{gathered}
$$

Considering the bulk concentration of dye equals the dynamic surface concentration over RHA, the mass balance equation for the entire system in terms of bulk concentration of the dye of volume $V$ and solid phase concentration $(Y)$ can be expressed as follows

$$
-V \frac{d C_{0}}{d t}=W \frac{d Y}{d t}
$$

where $W$ is the mass of RHA added to volume $V$ of well stirred dye solution. Incorporating Equation (3) into Equation (4), the unsteady state equation of bulk concentration thus becomes

$$
\begin{aligned}
& \frac{d C_{0}(t)}{d t}= \\
& -\frac{6 D_{0} W}{R^{2} \rho_{P} V}\left[C_{0}(t)-\sum_{n=1}^{\infty} \frac{D_{0} n^{2} \pi^{2}}{R^{2}} e^{\frac{-D_{0} n^{2} \pi^{2} t}{R^{2}}} \int_{0}^{t} C_{0}\left(t^{\prime}\right) e^{\frac{D_{0} n^{2} \pi^{2} t^{\prime}}{R^{2}}} d t^{\prime}\right]
\end{aligned}
$$

Equation (5) can be solved numerically in order to obtain the time evolution for bulk concentration. The initial condition for Equation (5) was taken as $C_{0}=C_{0, \text { in }}$ at $t=0$, where $C_{0, i n}$ is the initial bulk concentration of the dye. The unknown constant parameter in the expression namely the effective pore diffusivity $D_{0}$ was estimated by a global optimization technique in order to achieve the best fit of model prediction with experimental results.

\section{Computational Method}

Equation (5) was numerically solved by fourth order Runge-Kutta method with step size of $\Delta t^{*}=10^{-5}$ with a simultaneous global optimization of diffusivity $D_{0}$. The objective function for global optimization is

$$
E\left(D_{0}\right)=\frac{1}{4} \cdot \sum_{j=1}^{4} \sum_{i=1}^{9}\left(C_{0, i j}^{\bmod e l}-C_{0, i j}^{\exp }\right)^{2}
$$

Nine experimental data points $(i=1,9)$ distributed over the time span of $2.5 \mathrm{hrs}$ are sufficient enough for the system to reach equilibrium that are compared with the theoretical counterpart at the same instant of time. The calculated error, after squaring is summed and subsequently averaged for four different runs $(j=1,4)$, char- 
acterized by four different initial bulk concentrations. As the optimization problem is one dimensional, it was solved by simple Fibonacci search technique [21].

\section{Materials and Methods}

Rice husk ash (RHA) was collected from a local industry and was used without any pretreatment for our batch adsorption investigations using $\mathrm{MB}$ and $\mathrm{CR}$ dyes [E. MERCK grade] in the aqueous phase. A digital visible spectrophotometer (SYSTRONICS: Model-166) was used for spectral detection of color fixing $\lambda_{\max }$ values at 665 $\mathrm{nm}$ and $498 \mathrm{~nm}$ for MB and CR respectively. The particle size distribution of the RHA was done using sieve analysis (Table 1). From the screen analysis of the raw RHA sample the volume-surface mean diameter $\left(\bar{d}_{p}\right)$ was found to be $0.0184 \mathrm{~mm}$ which was utilized for model calculations. Scanning Electron Microscope (SEM) (Model S 3400N, Hitachi, Japan) analysis was also carried out for the RHA particles for determining the surface morphology. The SEM analysis clearly indicated the presence of irregular and highly porous structure of the RHA sample studied (see Figure 1 for the micrograph). The depletion of dye concentration owing to adsorption onto RHA was analyzed by determining the COD values of the samples following open reflux method recommended in APHA [22] and the percentage removal was calculated from the following formula

$$
\% \text { removal }=\frac{C_{0, \text { in }}-C_{0, \text { equi }}}{C_{0, \text { in }}} \times 100
$$

The range of variables in the present batch experimental programme were: Temperature $(\mathrm{K}): 303 \pm 1$; Adsorbate concentration: $50-300 \mathrm{mg} / \mathrm{L}$; Adsorbent dose: 5-100 g/L; Contact Time: 5-300 min; Shaker Speed: 160

Table 1. Particle size distribution of the Rice Husk Ash (RHA).

\begin{tabular}{cc} 
Sieve pore size (mm) & Weight of particles retained over sieve (\%) \\
\hline 2.000 & 0 \\
1.180 & 0 \\
0.600 & 3.2 \\
0.425 & 4.8 \\
0.212 & 42.7 \\
0.125 & 33.3 \\
0.075 & 16 \\
\hline
\end{tabular}

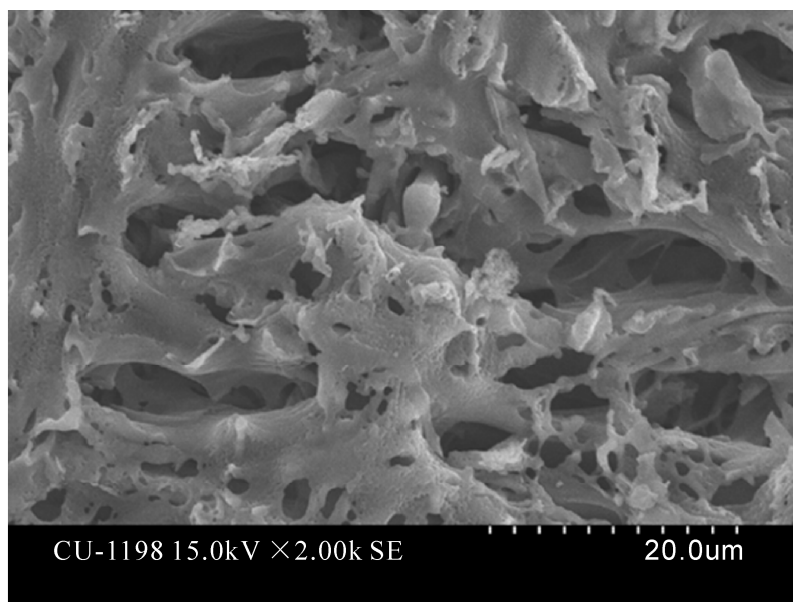

Figure 1. Micrograph of Rice Husk Ash (RHA) particles under SEM.

rpm; solution pH: 4, 7, 9.2, Natural pH (5.8 for MB Dye; 7.04 for CR Dye).

\section{Results and Discussion}

\subsection{Optimum Operating Conditions and the Adsorption Isotherms}

Batch adsorption was carried out to find out the effects of various parameters (like, the initial dye concentration, the adsorbent dosage, the solution $\mathrm{pH}$ and the contact time) on the percentage removal of dyes. These initial studies helped in determining the optimum operating conditions. It was observed from experimentations that the percentage removal monotonically decreased with the increase in the initial concentration of dyes and reached almost constant values for both the dyes after a contact time of $1 \mathrm{hr}$ beyond which there was no noticeable change in the percentage removal. Therefore, the equilibrium time was considered to be $1 \mathrm{hr}$ in this study. The percentage removal was also observed increased with the increase in the adsorbent dosage to a certain limiting value beyond which it levels off (Figure 2). The variation of percentage removal at a fixed adsorbent dosage with solution $\mathrm{pH}$ is shown in Figure 3 for different dyes under investigation. As can be seen from Figure 3 that the percentage removal was increased with the increase in $\mathrm{pH}$ for $\mathrm{MB}$ dye, in contrast it was decreased for $\mathrm{CR}$ with $\mathrm{pH}$ values. It might be attributed to the adsorbent surface basicity as well as acidity that might be responsible for showing such behavior of adsorption. This type of surface behavior can be represented by the following equations [23]

$$
\begin{gathered}
\text { Adsorbent-OH } \rightarrow \text { Adsorbent- }{ }^{-}+\mathrm{H}^{+} \\
\text {Adsorbent-OH }+\mathrm{H}^{+} \rightarrow \text { Adsorbent- } \mathrm{OH}_{2}^{+}
\end{gathered}
$$

Equation (8) indicates basicity of the adsorbent surface 


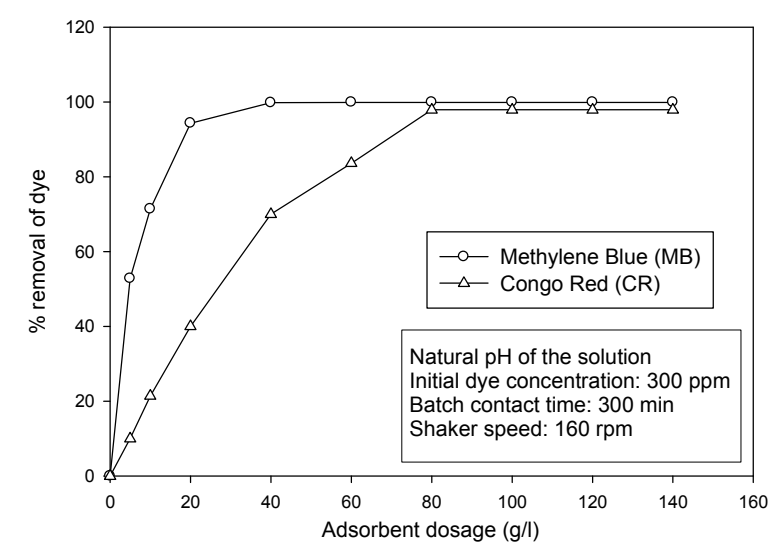

Figure 2. Variation of equilibrium percentage removal of dyes with adsorbent dosage.

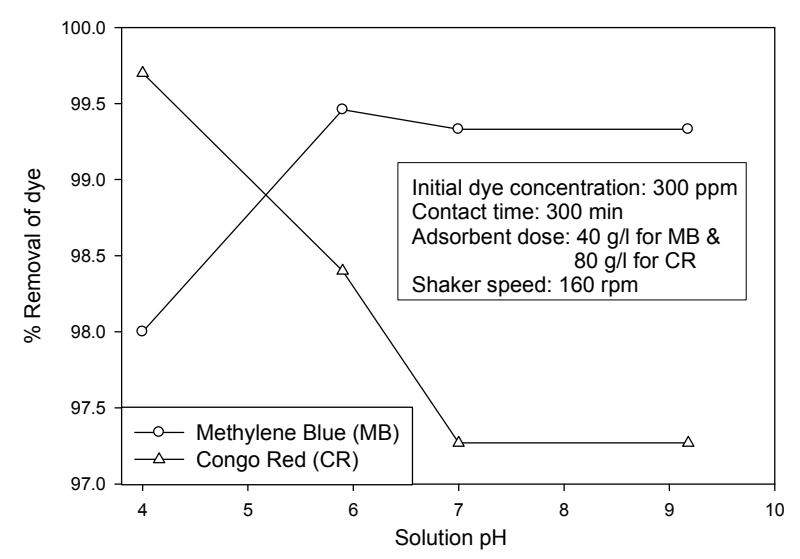

Figure 3. Variation of equilibrium percentage removal of dyes with $\mathrm{pH}$.

at higher $\mathrm{pH}$, while Equation (9) indicates adsorbent surface acidity at lower $\mathrm{pH}$. Therefore, $\mathrm{MB}$ being a cationic dye was adsorbed onto the RHA surface effectively at higher $\mathrm{pH}$ since the adsorbent surface attained basicity at higher $\mathrm{pH}$ per Equation (8). The adsorption beyond a $\mathrm{pH}$ of 6.0 was better here yielding better removal of MB. In contrast, CR being an anionic dye was adsorbed onto RHA surface effectively at lower $\mathrm{pH}$ since the adsorbent surface attained acidity at lower $\mathrm{pH}$ per Equation (9). The adsorption was however, observed deteriorated on increasing $\mathrm{pH}>4.0$ in this case. Therefore, the removal of CR on RHA by adsorptive mass transport was better at lower $\mathrm{pH}$. The optimum solution $\mathrm{pH}$ was found to be 6.0 for MB and 4.0 for CR from these initial studies. The optimum adsorbent dosage was found to be $40.0 \mathrm{~g} / \mathrm{L}$ and $80.0 \mathrm{~g} / \mathrm{L}$ for MB and CR dyes respectively.

Equilibrium studies were carried out under optimum operating conditions as described previously to determine the Langmuir adsorption isotherm parameters $\left(k_{0}\right.$ and $\left.Y_{S}\right)$. The linearized forms of the isotherm for dif- ferent dyes in terms of $\frac{1}{Y_{e t}}$ as a function of $\frac{1}{C_{0}}$ are shown in Figure 4 (for MB dye) and in Figure 5 (for CR dye). The Langmuir constants along with the correlation coefficients determined from the slope and intercept of the linear plots are presented in Table 2. The correlation coefficients clearly demonstrate that the Langmuir isotherm can well describe the equilibrium adsorption characteristics of the present system.

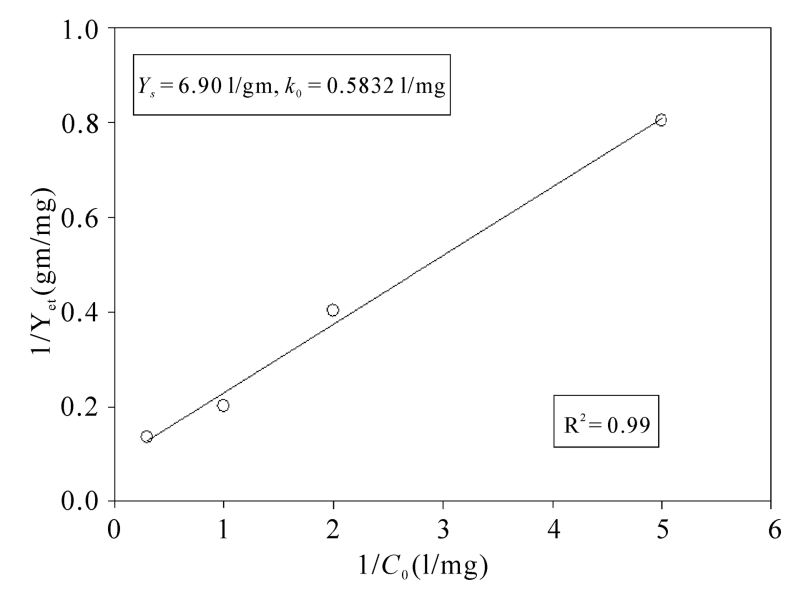

Figure 4. Langmuir plot for MB dye adsorption at optimum operating conditions.

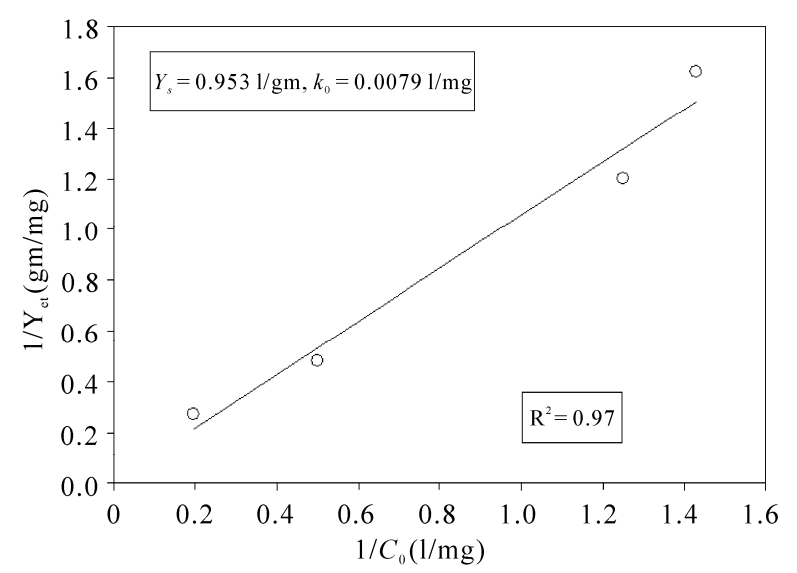

Figure 5. Langmuir plot for CR dye adsorption at optimum operating conditions.

Table 2. Values of Langmuir constants at optimum operating condition and statistical data.

\begin{tabular}{|c|c|c|c|}
\hline \multirow{2}{*}{$\begin{array}{l}\text { Types of dye } \\
\text { studied }\end{array}$} & \multicolumn{2}{|c|}{ Langmuir constants } & \multirow{2}{*}{$\begin{array}{l}\text { Correlation coef- } \\
\quad \text { ficient }\left(\mathrm{R}^{2}\right)\end{array}$} \\
\hline & $k_{0}(\mathrm{~L} / \mathrm{mg})$ & $Y_{S}(\mathrm{~L} / \mathrm{g})$ & \\
\hline Methylene Blue & 0.5832 & 6.90 & 0.99 \\
\hline Congo Red & 0.0079 & 0.953 & 0.97 \\
\hline
\end{tabular}




\subsection{Dynamic Characterization of the Concentration Profile}

The values of dimensionless concentration $\left(\frac{C_{0}}{C_{0, \text { in }}}\right)$ against time were generated numerically after solving Equation (5) with simultaneous optimization of the effective pore diffusion coefficient $\left(D_{0}\right)$. These values were compared with experimental values. Comparisons of such model predicted values with experimental data at four different initial concentrations of 50, 100, 200 and 300 $\mathrm{mg} / \mathrm{L}$ for both dyes in combination with RHA as adsorbent are shown in Figure 6 (for MB) and in Figure 7 (for $\mathrm{CR}$ ). It can be seen from these figures that the model prediction agreed reasonably well with the experimental data, with a maximum standard deviation of 0.0347 for $\mathrm{MB}$ and 0.0599 for CR. Clearly, this finding establishes the general validity of the proposed in describing the adsorp-

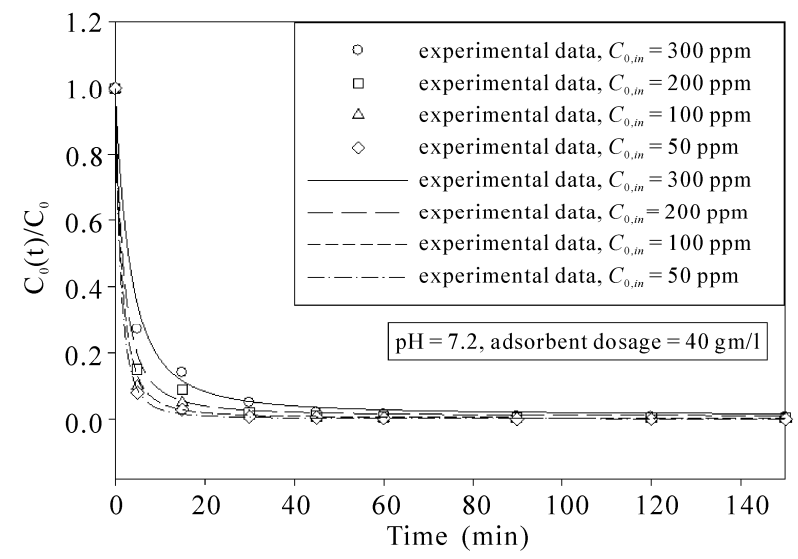

Figure 6. Variation of dimensionless bulk concentration with time for four different initial bulk concentrations of MB dye.

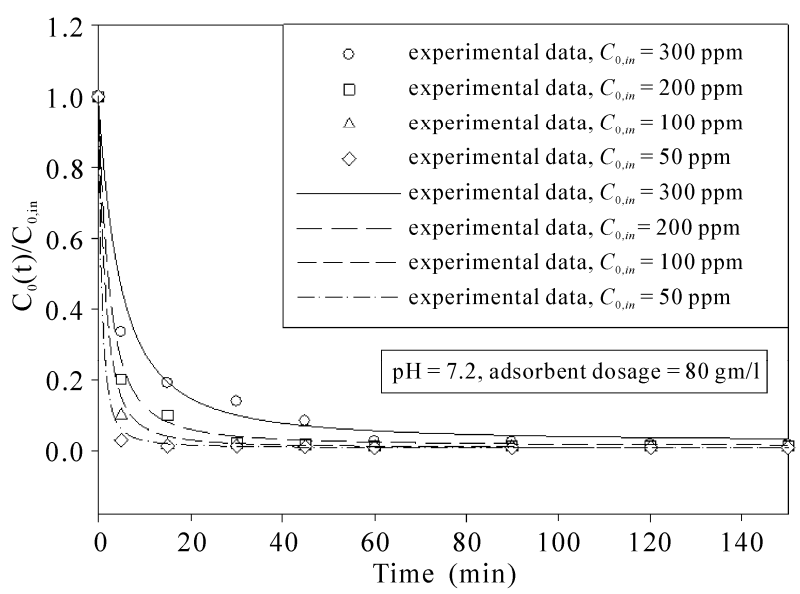

Figure 7. Variation of dimensionless bulk concentration with time for four different initial bulk concentrations of CR dye. tion of different dyes on RHA. The values of pore diffusivity of MB and CR dye molecules in RHA were determined from the present analysis and details of which are shown in Table 3. It can be seen from the table that the pore diffusivities of $\mathrm{MB}$ and $\mathrm{CR}$ dye molecules onto RHA were $1.34 \times 10^{-9} \mathrm{~m}^{2} / \mathrm{s}$ and $8.65 \times 10^{-10} \mathrm{~m}^{2} / \mathrm{s}$ respectively. Clearly, it demonstrates that $\mathrm{MB}$ dye molecules diffused faster than CR dye molecule resulting in better removal of $\mathrm{MB}$ dye. In terms of increasing order of pore diffusivity values, the dye molecule can be arranged as $\mathrm{MB}$, CR. Owing to relatively higher pore diffusivity value of $\mathrm{MB}$ dye molecule, further analysis will be carried out in respect of this molecule in order to avoid redundancies. The transient concentration distribution of MB dye molecules into the RHA particle was also evaluated using Equation (2) as shown in Figure 8. The findings of this work could be very much useful in the design and simulation of a packed bed adsorption column intended to be put into practice. Results thus establish the potential of RHA as an adsorbent for treating industrial dye containing toxic effluents.

\subsection{Effectiveness of the Proposed Model Compared with Other Adsorption- Diffusion Models}

In order to establish the gross effectiveness of the proposed adsorption-diffusion model, the predictions of the

Table 3. Values of effective pore diffusivity obtained by SCM and standard errors.

\begin{tabular}{ccccc}
\hline & Pore & \multicolumn{3}{c}{ Standard error } \\
\cline { 3 - 5 } Types of \\
dye studied & $\begin{array}{c}\text { diffusion, } \\
D_{0}\left(\mathrm{~m}^{2} / \mathrm{s}\right)\end{array}$ & Maximum & Minimum & Average \\
\hline $\begin{array}{c}\text { Methylene } \\
\text { Blue }\end{array}$ & $1.34 \times 10^{-9}$ & 0.0357 & 0.0043 & 0.0182 \\
\begin{tabular}{c} 
Congo Red \\
\cline { 3 - 5 }
\end{tabular} & $8.65 \times 10^{-10}$ & 0.0589 & 0.0142 & 0.0378 \\
\hline
\end{tabular}

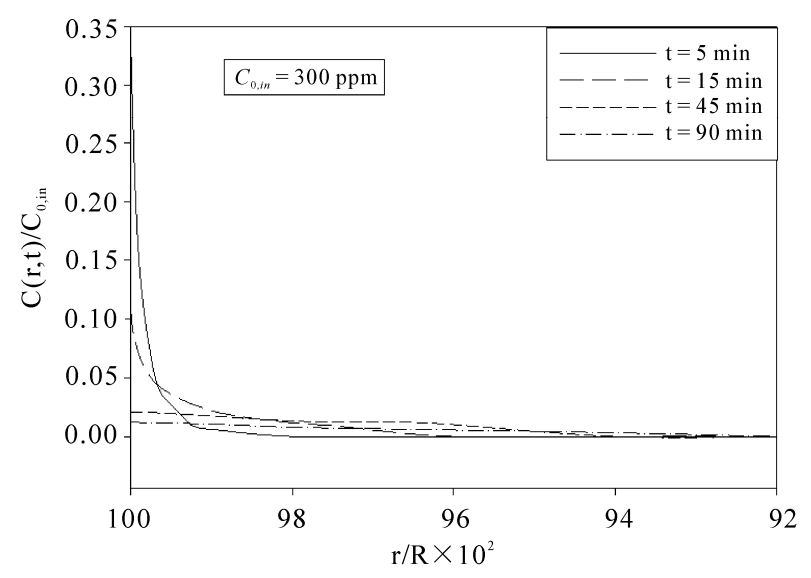

Figure 8. Degree of penetration of MB dye onto RHA particles. 
proposed model was compared with two standard adsorption-diffusion models, namely, the diffusion model according to Vermeulen's approximation [24] and the parabolic diffusion model [25].

According to Vermeulen's approximation of impregnated diffusion model the plot of $\ln \left(1-\mathrm{F}^{2}\right)$ as a function of time $(t)$ should give a straight line with a slope of $\frac{\pi^{2} \mathrm{D}_{0}}{\mathrm{R}}$, where $F=\frac{1-C_{0}^{*}(t)}{1-\left.C_{0}^{*}(t)\right|_{\text {equi }}}$ and $\left.C_{0}^{*}(t)\right|_{\text {equi }}$ is the dimensionless concentration at equilibrium. Values obtained from the two models (i.e., Vermeulen's and the proposed model) with respect to discrete experimental data points for RHA-MB dye system are compared and shown in Figure 9. The values of standard error of $0.4611\left(C_{0, \text { in }}=50 \mathrm{ppm}\right)$ and $0.872\left(C_{0, \text { in }}=300 \mathrm{ppm}\right)$ were obtained for Vermeulen's model; while the values of standard error of $0.326\left(C_{0, \text { in }}=50 \mathrm{ppm}\right)$ and 0.152 $\left(C_{0, \text { in }}=300 \mathrm{ppm}\right)$ were obtained for the proposed model, establishes that the proposed model yields much better result than Vermeulen's approximation coupled impregnated diffusion model.

The parabolic diffusion model, on the other hand, predicts a linear relationship between $\frac{F}{t}$ and $\frac{1}{t^{1 / 2}}$. Values obtained from the two models (i.e., parabolic diffusion model and the proposed model) for RHA-MB dye system are compared and shown in Figure 10. The values of standard error for the proposed model were 0.0049 $\left(C_{0, \text { in }}=50 \mathrm{ppm}\right)$ and $0.0043\left(C_{0, \text { in }}=300 \mathrm{ppm}\right)$, whereas the values of standard error for the Parabolic model were $0.0114\left(C_{0, \text { in }}=50 \mathrm{ppm}\right)$ and $0.0101\left(C_{0, \text { in }}=300 \mathrm{ppm}\right)$,

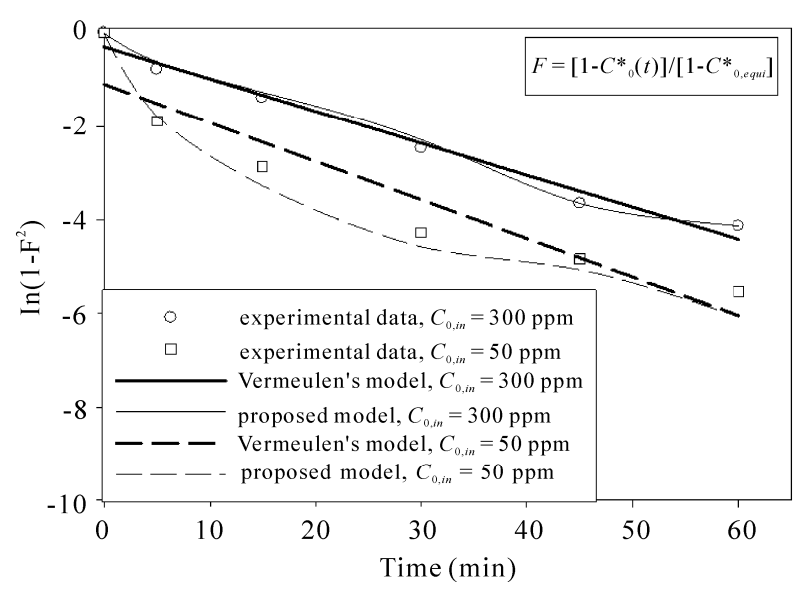

Figure 9. Comparison of the proposed model with the diffusion model according to Vermeulen for $\mathrm{MB}$.

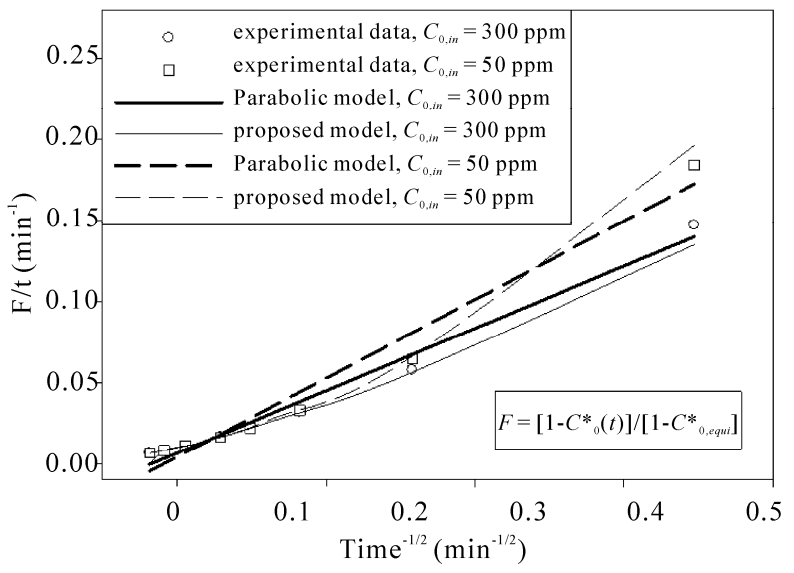

Figure 10. Comparison of the proposed model with the parabolic diffusion model for MB dye.

establishes that the proposed adsorption-diffusion model yields superior result over the other two standard models. Clearly, the comparative analyses elicit the superiority of the general applicability of the proposed model over the Parabolic model and Vermeulen's approximation coupled impregnated diffusion model in ascribing the dynamic behavior of the present system under different parametric conditions.

\section{Conclusions}

The performance of RHA obtained from local rice mill was analyzed as an adsorbent for the removal of MB and CR dyes from their synthetic aqueous solution. SEM analysis revealed the irregular and porous surfaces suitable for adsorption. Experimentation under batch mode was carried out to generate baseline data, like the equilibrium time for adsorption for dyes and optimum adsorbent dosage as well as solution $\mathrm{pH}$. These baseline data were used to validate a proposed adsorption-diffusion model formulated to simulate the adsorption process dynamics. Latter, a global optimization technique was adopted in order to evaluate values of the effective pore diffusivity for different dyes in the RHA. Additionally, the performance of the present system was also characterized using other two standard adsorption-diffusion models, namely the Parabolic model and Vermeulen's approximation coupled impregnated diffusion model. Comparison of the performances of the proposed model and other two standard adsorption-diffusion models clearly demonstrated the superiority of the proposed model over two other two models in analyzing the behavior of the present system. The pore diffusivity values evaluated as an outcome of the present analysis could be gainfully used in the modeling as well as simulation of the industrial adsorption column. 


\section{References}

[1] G. McKay, M. S. Otterburn and J. A. Aga, "Fuller's Earth and Fired Clay as Adsorbent for Dyestuffs," Water, Air, and Soil Pollution, Vol. 24, No. 3, March 1985, pp. 307322.

[2] A. Tor and Y. Cengeloglu, "Removal of Congo Red from Aqueous Solution by Adsorption onto Acid Activated Red Mud," Journal of Hazardous Materials, Vol. 138, No. 2, November 2006, pp. 409-415.

[3] A. Özer and G. Dursun, "Removal of Methylene Blue from Aqueous Solution by Dehydrated Wheat Bran Carbon," Journal of Hazardous Materials, Vol. 146, No. 1-2, July 2007, pp. 262-269.

[4] B. H. Hameed, A. T. M. Din and A. L. Ahmad, "Adsorption of Methylene Blue onto Bamboo-Based Activated Carbon: Kinetics and Equilibrium Studies," Journal of Hazardous Materials, Vol. 141, No. 3, March 2007, pp. 819-825.

[5] R. Han, Y. F. Wang, W. H. Yu, W. H. Zou, J. Shi and H. M. Liu, "Biosorption of Methylene Blue from Aqueous Solution by Rice Husk in a Fixed-Bed Column," Journal of Hazardous Materials, Vol. 141, No. 3, March 2007, pp. 713-718.

[6] H. Lata, V. K. Garg and R. K. Gupta, "Removal of a Basic Dye from Aqueous Solution by Adsorption Using Parthenium Hysterophorus: An Agricultural Waste," Dyes and Pigments, Vol. 74, No. 3, 2007, pp. 653-658.

[7] M. I. El-Khaiary, "Kinetics and Mechanism of Adsorption of Methylene Blue from Aqueous Solution by Nitric-Acid Treated Water-Hyacinth," Journal of Hazardous Materials, Vol. 147, No. 1-2, August 2007, pp. 2836.

[8] V. J. P. Vilar, C. M. S. Botelho and R. A. R. Boaventura, "Methylene Blue Adsorption by Algal Biomass Based Materials: Biosorbents Characterization and Process Behavior," Journal of Hazardous Materials, Vol. 147, No. 1-2, August 2007, pp. 120-132.

[9] K. V. Kumar, K. Porkodi and F. Rocha, "Isotherms and Thermodynamics by Linear and Non-Linear Regression Analysis for the Sorption of Methylene Blue onto Activated Carbon: Comparison of Various Error Functions," Journal of Hazardous Materials, Vol. 151, No. 2-3, March 2007, pp. 794-804.

[10] W.-T. Tsai, H.-C. Hsub, T.-Y. Su, K.-Y. Lin and C.-M. Lin, "Removal of Basic Dye (Methylene Blue) from Wastewaters Utilizing Beer Brewery Waste," Journal of Hazardous Materials, Vol. 154, No. 1-3, June 2008, pp. 73-78.

[11] M. F. Zhao, Z. B. Tang and P. Liu, "Removal of Methylene Blue from Aqueous Solution with Silica Nano-Sheets Derived from Vermiculite," Journal of Hazardous Materials, Vol. 158, No. 1, October 2008, pp. 43-51.

[12] L. Wang and A. Q. Wang, "Adsorption Behaviors of Congo Red on the $\mathrm{N}, \mathrm{O}$-carboxymethyl-chitosan/montmo- rillonite Nanocomposite," Chemical Engineering Journal, Vol. 143, No. 1-3, September 2008, pp. 43-50.

[13] E. Bulut, M. Özacar and İ. A. Şengil, "Equilibrium and Kinetic Data and Process Design for Adsorption of Congo Red onto Bentonite," Journal of Hazardous Materials, Vol. 154, No. 1-3, June 2008, pp. 613-622.

[14] B. H. Hameed and A. A. Ahmad, "Batch Adsorption of Methylene Blue from Aqueous Solution by Garlic Peel, an Agricultural Waste Biomass," Journal of Hazardous Materials, Vol. 164, No. 2-3, May 2009, pp. 870-875.

[15] V. Vimonses, S. M. Lei, B. Jin, C. W. K. Chow and C. Saint, "Kinetic Study and Equilibrium Isotherm Analysis of Congo Red Adsorption by Clay Materials," Chemical Engineering Journal, Vol. 148, No. 2-3, May 2009, pp. 354-364.

[16] S. Chatterjee, M. W. Lee and S. H. Woo, "Influence of Impregnation of Chitosan Beads with Cetyl Trimethyl Ammonium Bromide on their Structure and Adsorption of Congo Red from Aqueous Solutions," Chemical Engineering Journal, Vol. 155, No. 1-2, December 2009, pp. 254-259.

[17] A. Afkhami and R. Moosavi, "Adsorptive Removal of Congo Red, a Carcinogenic Textile Dye, from Aqueous Solutions by Maghemite Nanoparticles," Journal of Hazardous Materials, Vol. 174, No. 1-3, February 2010, pp. 398-403.

[18] G. C. Panda, S. K. Das, A. K. Guha, "Jute Stick Powder as a Potential Biomass for the Removal of Congo Red and Rhodamine B from their Aqueous Solution," Journal of Hazardous Materials, Vol. 164, No. 1, May 2009, pp. 374-379.

[19] P. R. Jena, S. De, J. K. Basu, “A Generalized Shrinking Core Model Applied to Batch Adsorption," Chemical Engineering Journal, Vol. 95, No. 1-3, September 2003, pp. 143-154.

[20] H. S. Carshlaw and J. C. Jaeger, "Conduction of Heat in Solids," 2nd Edition, Clarendon, Oxford, 1959.

[21] S. G. Beveridge and R. S. Schector, "Optimization: Theory and Practice," McGraw-Hill, Inc, New York, 1970.

[22] American Public Health Association, "Standard Methods for Examination of Water and Wastewater," 20th Edition, Washington, D.C., New York, 1998.

[23] E. N. E. Qada, S. J. Allen and G. M. Walker, “Adsorption of Basic Dyes from Aqueous Solution onto Activated Carbons," Chemical Engineering Journal, Vol. 135, No. 3, February 2008, pp. 174-184.

[24] V. J. Inglezakis and H. P. Grigoropoulous, "Applicability of Simplified Models for the Estimation of Ion Exchange Diffusion Coefficient in Zeolite," Journal of Colloid and Interface Science, Vol. 234, No. 2, February 2001, pp. 434-441.

[25] C. Aharon, D. L. Sparks, C. Levinson, I. Ravina, "Kinetics of Soil Chemical Reactions: Relationship between Empirical Equations and Diffusion Models," Soil Science Society of America Journal, Vol. 62, 1998, pp. 622-624. 


\section{Nomenclature}

$C(r, t)$ Concentration of dye at time $t$ and at radial position $r$ within the RHA particle

$C_{0}(t)$ or $C_{0}$ Dye concentration in the bulk solution at any time $t$

$C_{0, \text { equi }}$ Equilibrium dye concentration in the bulk solution

$C_{0, \text { in }}$ Initial dye concentration in the bulk solution

$C_{0}^{*}$ Dimensionless concentration in the bulk $\left(=\frac{C_{0}}{C_{0, \text { in }}}\right)$

$C_{0, i j}^{* \text { model }}$ Dimensionless concentration parameter according to model

$C_{0, i j}^{* \exp }$ Dimensionless concentration parameter according to experiment

CR Congo Red dye

$D_{0}$ Effective pore diffusion coefficient $\bar{d}_{p}$ Volume surface mean diameter

$E\left(D_{0}\right)$ Objective function for global optimization

$F$ Parameter defined in the Subsection 5.3.

$k_{0}$ Langmuir isotherm constant

MB Methylene Blue dye

$R$ Mean radius of the RHA particles $\left(=\frac{\bar{d}_{p}}{2}\right)$

$r$ Radial coordinate

RHA Rice Husk Ash

$t$ Time

$t^{\prime}$ Dummy variable used in Equation (2)

$V$ Volume of stirred solution

$W$ Mass of RHA added

$Y_{s}$ Langmuir isotherm constant

$Y_{e t}$ Adsorbed amount in equilibrium with bulk concentration at time $t$

$\rho_{P}$ Bulk density of RHA particles 